\title{
Lung Function Decline in Adult Asthmatics-A 10-Year Follow-Up Retrospective and Prospective Study
}

\author{
Salvatore Bucchieri ${ }^{1}$, Pietro Alfano ${ }^{1}$, Palma Audino ${ }^{1}$, Fabio Cibella ${ }^{1}$, Giovanni Fazio ${ }^{2, *}$, Salvatore Marcantonio ${ }^{3}$ \\ and Giuseppina Cuttitta ${ }^{1}$ \\ 1 Institute for Biomedical Research and Innovation, National Research Council of Italy, Via U.La Malfa, 153, \\ 90146 Palermo, Italy; salvatore.bucchieri@irib.cnr.it (S.B.); pietro.alfano@irib.cnr.it (P.A.); \\ palma.audino@hotmail.it (P.A.); fabio.cibella@irib.cnr.it (F.C.); giuseppina.cuttitta@irib.cnr.it (G.C.) \\ 2 Triolo Zanca Clinic, Piazza Fonderia, 23, 90133 Palermo, Italy \\ 3 Quality, Planning and Strategic Support Area, University of Palermo, Piazza Marina, 61, 90133 Palermo, Italy; \\ salvatore.marcantonio@unipa.it \\ * Correspondence: faziogiova@gmail.com
}

Citation: Bucchieri, S.; Alfano, P.; Audino, P.; Cibella, F.; Fazio, G.;

Marcantonio, S.; Cuttitta, G. Lung Function Decline in Adult Asthmatics-A 10-Year Follow-Up Retrospective and Prospective Study. Diagnostics 2021, 11, 1637. https:// doi.org/10.3390/diagnostics11091637

Academic Editor: Felix G. Meinel

Received: 19 August 2021

Accepted: 3 September 2021

Published: 7 September 2021

Publisher's Note: MDPI stays neutral with regard to jurisdictional claims in published maps and institutional affiliations.

\begin{abstract}
Asthma may have an impact on lung function decline but conflicting results are reported in forced expiratory volume in one second $\left(\mathrm{FEV}_{1}\right)$ decline. We aimed to describe the changes in $\mathrm{FEV}_{1}$ in lifelong non-smoking adult asthmatic outpatients during a 10-year follow-up comparing years 1-5 (1st period) with years 6-10 (2nd period) to assess factors affecting these changes. A total of 100 outpatients performed spirometry every 3 months during a 10 -year survey. $\mathrm{FEV}_{1} / \mathrm{Ht}^{3}$ slope values of the 2 nd period reduced significantly respect to the 1 st period $(p<0.0001)$. $\mathrm{FEV}_{1}$ slopes of years 1-5 and 6-10 were inversely associated with $\mathrm{FEV}_{1}$ at enrolment ( $p=0.02, p=0.01$, respectively). Reversibility and variability $\mathrm{FEV}_{1}$ showed a significant effect on the 1 st period slopes $(p=0.01$ and $p<0.04$, respectively). Frequent exacerbators in the 1 st year had steeper $\mathrm{FEV}_{1} / \mathrm{Ht}^{3}$ slopes in the 1 st period ( $p=0.01)$. The number of subjects using higher doses of ICS was significantly lower at the 10 th years respect to the 5 th and the 1 st year $(p<0.001, p=0.003$, respectively). This study shows that $\mathrm{FEV}_{1}$ decline in treated adult asthmatics non-smokers, over 10-year follow-up, is not constant. In particular, it slows down over time, and is influenced by $\mathrm{FEV}_{1}$ at enrolment, reversibility, variability $\mathrm{FEV}_{1}$ and exacerbation score in the 1 st year.
\end{abstract}

Keywords: asthma; $\mathrm{FEV}_{1}$ decline; exacerbation; reversibility; inhaled steroids

\section{Introduction}

Conflicting results exist regarding lung function decline rates in asthmatics: in forced expiratory volume in one second $\left(\mathrm{FEV}_{1}\right)$, rates range from almost normal [1,2] to those expected in chronic obstructive pulmonary disease (COPD) [3,4]. Asthma may have a significant impact on lung function decline $[5,6]$ and recent studies suggest that long-term treatment with inhaled steroids may decrease $\mathrm{FEV}_{1}$ decline $[7,8]$. However, if little is known about other factors associated with $\mathrm{FEV}_{1}$ decline in adult asthmatics, the relationship of the characteristics of such patients and biomarkers of progression for airflow limitation, a functional consequence of airway remodelling, is considered important in the management of asthma [9]. We previously reported that longer disease duration may decrease the decline rate in asthmatics during a five-year period [10]: this interaction may add to the effects of asthma treatment.

We studied a sample of 100 non-smoker asthmatic outpatients followed-up by spirometry every 3 months during a 10-year survey. The purpose of this study was to evaluated the longitudinal $\mathrm{FEV}_{1}$ changes during this period, comparing years 1-5 (1st period) with years 6-10 (2nd period) also determining possible factors affecting functional decline. 


\section{Methods}

A database was established in 2001. In this database were recorded the longitudinal data over the present: patients' demographic characteristics, asthma symptoms based on Global Initiative for Asthma (GINA) guidelines [11], exacerbations and treatment details including frequency of consultation, rescue therapy, hospitalization, type and dose of asthma medications, respiratory variables relevant to the first visit and their subsequent visits. Data for this study are from the National Research Council of Palermo, a public primary care institution comprising a pneumological clinical. A total of 1930 patients were recorded in the database over the period 2001-2012.

Inclusion criteria were: consecutive lifelong non-smoking asthmatics followed-up over a 10-year period in an outpatient asthma clinic; a follow-up visit every three months for every year of observation, inclusive of pulmonary evaluation with spirometry. We enrolled 100 non-smoking asthmatics (aged 18-66 years, $41 \mathrm{M}$ ). The anthropometric, clinical, and functional characteristics at enrolment are presented in Table $1 . \mathrm{FEV}_{1}$ rate of decline compared with other studies are presented in Table 2.

Table 1. Anthropometric, clinical, and pulmonary functional characteristics at enrolment, according to sex.

\begin{tabular}{|c|c|c|c|}
\hline & Females (No 59) & Males (No 41) & $p$ Value \\
\hline Age at enrolment & $49(35-55)$ & $43(30-53)$ & 0.04 \\
\hline Body mass index & $25(22-30)$ & $27(23-28)$ & N.S. \\
\hline Age of disease onset & $33(19-43)$ & $24(12-38)$ & N.S. \\
\hline Disease duration & $12(7-21)$ & $15(5-20)$ & N.S. \\
\hline $\mathrm{FEV}_{1}$ at enrolment & $85(70-97)$ & $80(70-91)$ & N.S. \\
\hline FVC at enrolment & $105(93-114)$ & $98(96-109)$ & N.S. \\
\hline $\mathrm{FEV}_{1} / \mathrm{FVC}$ at enrolment (absolute, $\%$ ) & $69(61-75)$ & $68(58-73)$ & N.S. \\
\hline $\mathrm{FEV}_{1}$ rev, \% & $16(9-33)$ & $23(12-51)$ & N.S. \\
\hline Allergic sensitization (No, \%) & $41(69)$ & $28(68)$ & N.S. \\
\hline Rhinitis (No, \%) & $40(68)$ & $26(63)$ & N.S. \\
\hline Stage 1 Gina treatment $(\mathrm{No}, \%)$ & $12(20)$ & $8(19)$ & N.S. \\
\hline Stage 2 Gina treatment $(\mathrm{No}, \%)$ & $22(37)$ & $15(37)$ & N.S. \\
\hline Stage 3 Gina treatment (No, \%) & $25(43)$ & $18(44)$ & N.S. \\
\hline
\end{tabular}

Data are presented as median and IQ range unless noted otherwise, separately for gender. None of the differences was significant between male (M) and female (F) subgroups, (Mann-Whitney $U$-test, $\chi^{2}$ test) except for Age at enrolment.

Table 2. Overall $\mathrm{FEV}_{1}$ rate of decline compared with other studies. $\mathrm{FEV}_{1}$ decline values were separately calculated for a male and a female.

\begin{tabular}{|c|c|c|c|c|}
\hline & \multicolumn{2}{|c|}{ Reference } & \multirow[t]{2}{*}{ Asthma } & \multirow[t]{2}{*}{ COPD } \\
\hline & $\mathbf{M}$ & $\mathbf{F}$ & & \\
\hline Quanjer (Bull Eur Physiopath Respir 1983) & $29 \mathrm{~mL} /$ year & $25 \mathrm{~mL} /$ year & & \\
\hline Lange N Engl J Med 1998 & & & $38 \mathrm{~mL} /$ year & \\
\hline Peat Eur J Respir Dis 1987 & & & $50.5 \mathrm{~mL} /$ year & \\
\hline Fletcher 1976 (libro) & & & $22 \mathrm{~mL} /$ year & \\
\hline Cuttitta Chest 2002 & & & 40 & $41.3 \mathrm{~mL} /$ year \\
\hline Burrows 1986 & & & $65 \mathrm{~mL} /$ year & $70 \mathrm{~mL} /$ year \\
\hline Mannino Soriano (Am J Respir Crit Care Med 2009) & $18 \mathrm{~mL} /$ year & & & \\
\hline Kalhan R (Am J Med 2010) Framingham & 19.6 & $17.6 \mathrm{~mL} /$ year & & \\
\hline O' Byrne PM (Am J Respir Crit care Med 2009) & 27-34 mL/year & & & \\
\hline
\end{tabular}

At enrolment, personal history of bronchial asthma was confirmed by $\mathrm{FEV}_{1}$ reversibility $\left(\mathrm{FEV}_{1, \mathrm{rev}}\right)$ after inhalation of $400 \mu \mathrm{g}$ salbutamol [11,12]. In the presence of suggestive asthma symptoms without immediate reversibility, subjects underwent a course of oral steroids (OS): a new functional assessment was performed and long-term reversibility computed. 
Skin prick tests were performed with a panel including the most common aeroallergens, plus positive and negative control (Stallergenes Italia S.r.l), following EAACI recommendations. Allergic sensitization was indicated by at least one positive skin prick test [13].

During the follow-up, subjects underwent clinical and spirometric evaluations every three months and therapeutic recommendations were repeated. Patients were treated according to GINA guidelines [11]. In case of exacerbation, patients could receive telephonic counselling or unscheduled visit.

An inhaled corticosteroid (ICS) score was computed on the basis of daily ICS dose in $\mu \mathrm{g}$ : Low $\leq 500$; Moderate > 500 and $\leq 1000$; High > 1000. Cycles of short-term OS were used for computing the asthma exacerbations. The number of exacerbations during the 1st, 5 th, and 10th years of follow-up were recorded. Subjects with a number of OS $\geq 2$ were identified as frequent exacerbators, while those with OS $<2$ were infrequent exacerbators.

$\mathrm{FEV}_{1}$ variability, as expression of bronchial responsiveness [14] was calculated at the 1st, 5 th, and 10th year of follow-up, following the formula: $\left(\mathrm{FEV}_{1, \max }-\mathrm{FEV}_{1, \text { min }}\right) / \mathrm{FEV}_{1 \text {,pred }}$ $\times 100 . \mathrm{FEV}_{1 \text {, max }}$ and $\mathrm{FEV}_{1 \text {, min }}$ were the maximum and minimum $\mathrm{FEV}_{1}$ recorded during the 1st, 5 th, and 10th years of follow-up, and $\mathrm{FEV}_{1 \text {,pred }}$ was the corresponding individual predicted $\mathrm{FEV}_{1}$.

To compare all subjects independently of height, individual $\mathrm{FEV}_{1}$ data were normalized for the subject's height at the third power $\left(\mathrm{FEV}_{1} / \mathrm{Ht}^{3}, \mathrm{~L} / \mathrm{m}^{3} / \mathrm{y}\right)$ [15]. For each year of follow-up, the best $\mathrm{FEV}_{1}$ measure in each 6-month period was analysed [16]. Thus, in the follow-up, $20 \mathrm{FEV}_{1} / \mathrm{Ht}^{3}$ values resulted for each subject. The relationship between $\mathrm{FEV}_{1} / \mathrm{Ht}^{3}$ values as dependent variable and year (or year fractions) as independent variable was treated by linear regression analysis to obtain individual slopes to the 1st (slope $\mathrm{FEV}_{1} / \mathrm{Ht}^{3}$-1st period) and 2nd period (slope $\mathrm{FEV}_{1} / \mathrm{Ht}^{3}$-2nd period). The individual differences between slopes were calculated as differences between the slope of the 6th-10th year period and slope of the 1st-5th year period $\left(\Delta\right.$ slope $\left.\mathrm{FEV}_{1} / \mathrm{Ht}^{3}\right)$.

Slopes were tested against the investigated variables (unless otherwise indicated, continuous variables were dichotomized using the median value): gender, age at enrolment ( $<47.5$ and $\geq 47.5$ years), age of disease onset ( $<29$ and $\geq 29$ years), body mass index (BMI, $<26$ and $\left.\geq 26 \mathrm{Kg} / \mathrm{m}^{2}\right), \mathrm{FEV}_{1}$ at enrolment (as continuous variable), $\mathrm{FEV}_{1}$ variability ( $<11.3 \%$ and $\geq 11.3 \%$ ), reversibility $\left(\mathrm{FEV}_{1 \text {,postBD }} \geq 12 \%\right.$ respect to pre-bronchodilator $\left.\mathrm{FEV}_{1}\right)$, disease duration ( $<13$ years and $\geq 13$ years), allergic sensitization (Yes/No), rhinitis (Yes/No), ICS score (Low, Moderate, High) and exacerbation score (frequent/infrequent exacerbators).The study was approved by the Local Institutional Ethics Committee (authorization reference number 7/2013).

\section{Statistical Analysis}

Differences in frequency distribution of variables were evaluated by $\chi^{2}$ test, median differences, for not normally distributed variables, were evaluated by U Mann-Whitney tests for unpaired sample and by Wilcoxon test for paired sample.

Correlation between continuous variables was investigated using Spearman Rank Correlation.

All computations were performed by StatView statistical software package (SAS Institute, Cary, NC, USA). A probability level of $p<0.05$ was selected as statistically significant.

\section{Results}

\subsection{FEV 1 Decline}

The $\mathrm{FEV}_{1} / \mathrm{Ht}^{3}$ slope values for the two periods were not significantly different for gender (Mann-Whitney $U$ test). All $\mathrm{FEV}_{1} / \mathrm{Ht}^{3}$ slopes in the 1st period showed negative values whereas in the 2 nd period the slopes were significantly less negative than 1 st period slopes or positive (Wilcoxon test, $p<0.0001$ ). The median $\mathrm{FEV}_{1} / \mathrm{Ht}^{3}$ slope computed on the whole population sample was $-0.010 \mathrm{~L} / \mathrm{m}^{3} /$ year (range -0.079 to -0.0004 ) for years 
1-5 and $-0.006 \mathrm{~L} / \mathrm{m}^{3} /$ year (range -0.038 to +0.038 ) for years $6-10$ (Figure 1 ). In years $1-5$, $\mathrm{FEV}_{1}$ loss was $42.5 \mathrm{~mL}$ /year, computed for a $1.62 \mathrm{~m}$ tall subject (median height of sample); it was $25.5 \mathrm{~mL} /$ year, in years 6-10. A significant inverse relationship was found between $\Delta$ slope $\mathrm{FEV}_{1} / \mathrm{Ht}^{3}$ and slope $\mathrm{FEV}_{1} / \mathrm{Ht}^{3} 1-5$ year $(p<0.0001$ Spearman Rank Correlation) (Figure 2).

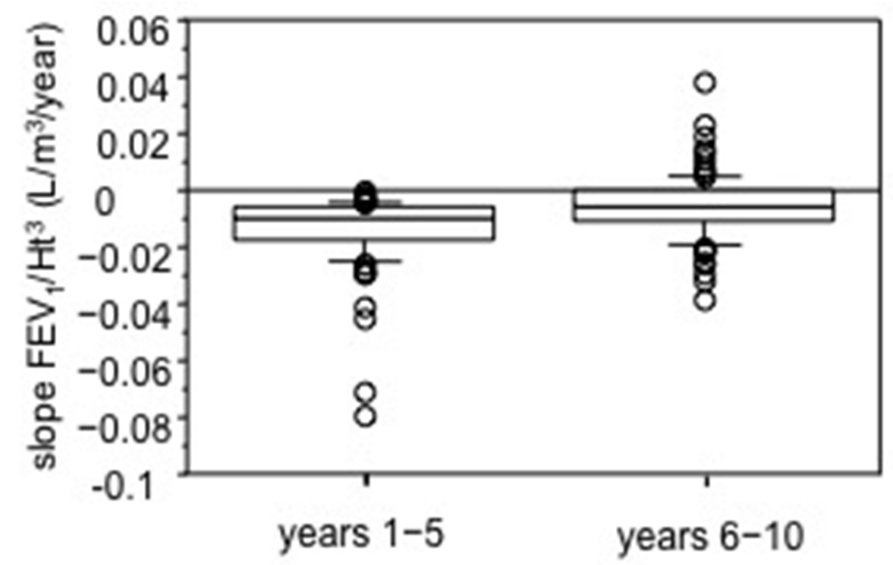

Figure 1. Slope values of relationships between height-adjusted $\mathrm{FEV}_{1}$ and time $\left(\mathrm{L} / \mathrm{m}^{3} /\right.$ year), separately for years 1-5 and 6-10. Bars indicate (from the bottom to the top) 10 th, 25 th, 50 th (median), 75 th and 90th percentiles. Values below 10th and above 90th percentiles are plotted as circles. A significant difference was found $(p<0.0001$, Wilcoxon test).

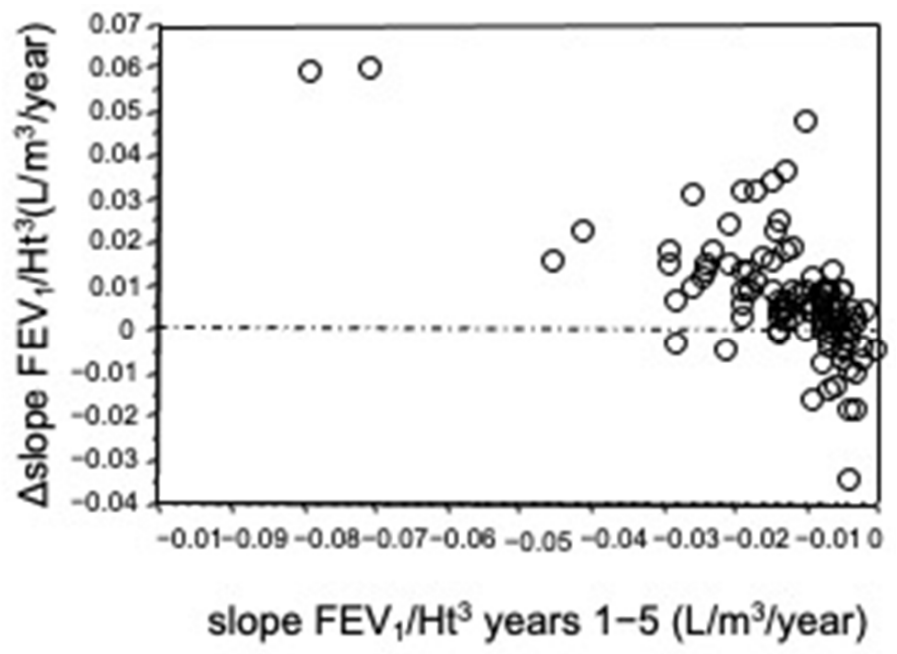

Figure 2. Relationship between the individual differences between the slope of the 6th-10th year period and slope of the 1 st -5 th year period $\left(\Delta\right.$ slope $\left.\mathrm{FEV}_{1} / \mathrm{Ht}^{3}\right)$ and slope $\mathrm{FEV}_{1}$ years $1-5$. A significant inverse correlation was found ( $p<0.0001$, Spearman Rank Correlation).

\subsection{Determinants of FEV $V_{1}$ Decline}

A significant inverse correlation was found between the $\mathrm{FEV}_{1}$ slopes of years 1-5 and $\mathrm{FEV}_{1}$ at enrolment, expressed as percent of predicted ( $p=0.02$, Spearman Rank Correlation); such a correlation was also found for years 6-10 ( $p=0.01)$ (Figure 3, Panels A and B).

Subjects with $\mathrm{FEV}_{1}$ reversibility showed steeper $\mathrm{FEV}_{1}$ slopes in years 1-5 with respect to subjects without reversibility ( $p=0.01$, Mann-Whitney $U$ test) but no significant effect of reversibility was observed on $\mathrm{FEV}_{1}$ slopes for years 6-10 (Figure 4).

$\mathrm{FEV}_{1}$ variability at the 1 st year had a significant effect on lung function decline in the 1st period: subjects with $\mathrm{FEV}_{1}$ variability $\geq 12 \%$ showed significantly steeper slopes in years 1-5 ( $p<0.04$, Mann-Whitney $U$ test) compared to subjects with lower variability. No 
significant effect on $\mathrm{FEV}_{1}$ slopes for years 6-10 was observed for subjects with high and low $\mathrm{FEV}_{1}$ variability at 1 st year (Figure 5).
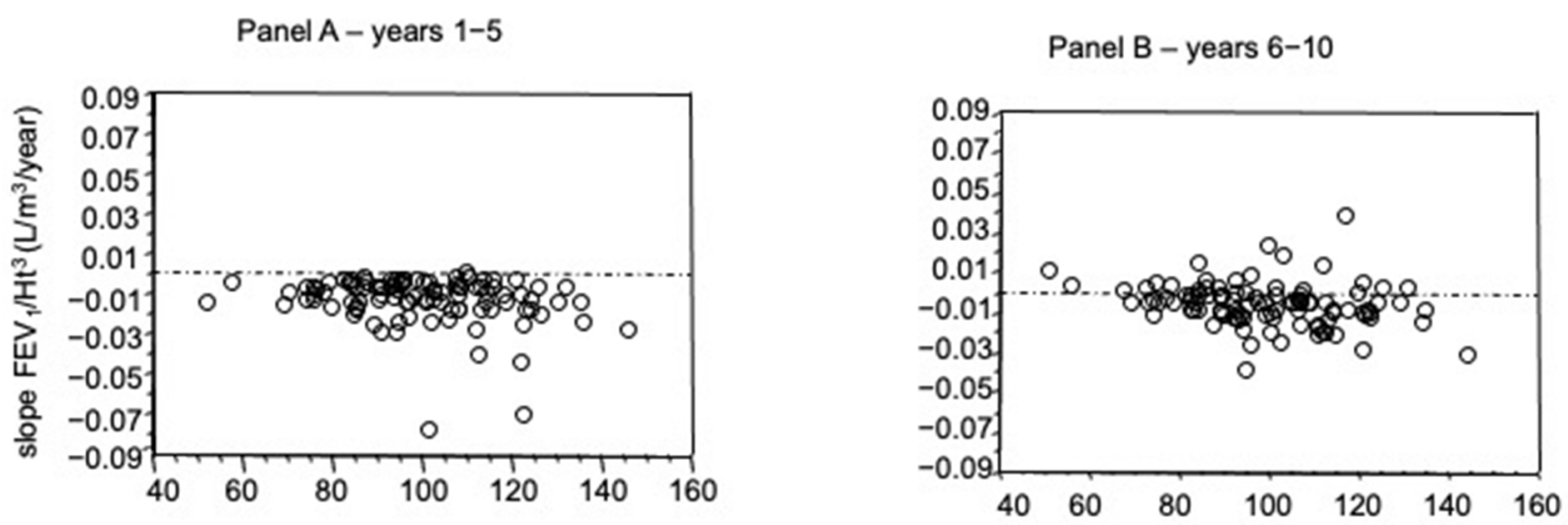

Figure 3. Relationships between slope values of relationships between height-adjusted $\mathrm{FEV}_{1}$ and time $\left(\mathrm{L} / \mathrm{m}^{3} /\right.$ year) for years 1-5 (Panel A) and for years 6-10 (Panel B) and FEV 1 at enrolment (\% of predicted). Both correlations were significant $(p=0.02$ and $p=0.01$, respectively, Spearman Rank Correlation).

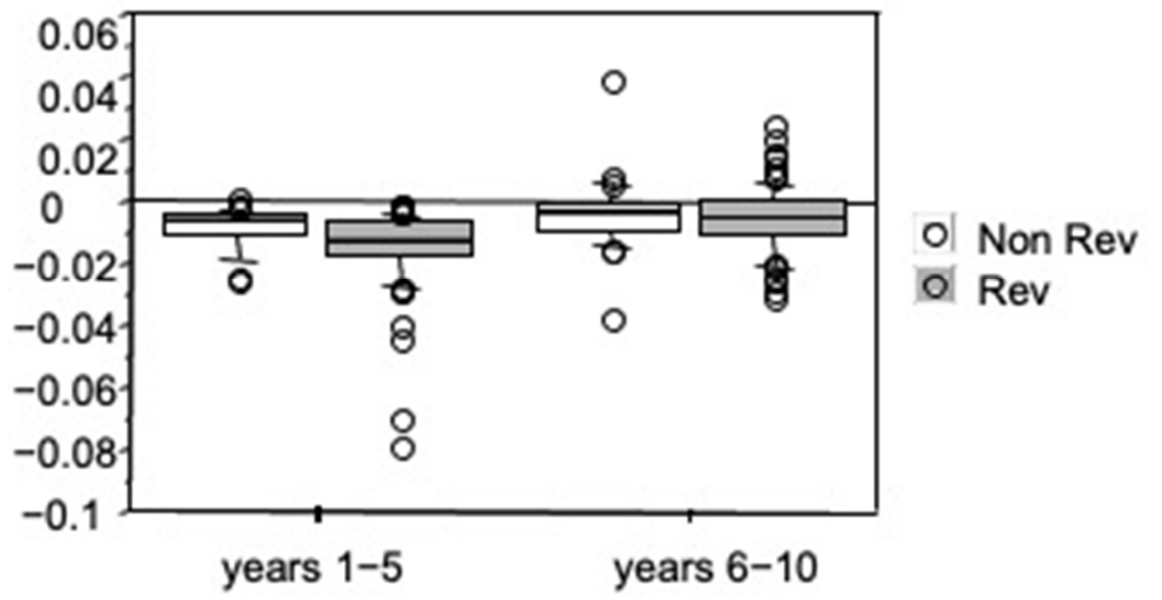

Figure 4. Slope values of relationships between height-adjusted $\mathrm{FEV}_{1}$ and time $\left(\mathrm{L} / \mathrm{m}^{3} /\right.$ year) during years 1-5 and years 6-10, separately for subjects with or without $\mathrm{FEV}_{1}$ reversibility at enrolment. Bars indicate (from the bottom to the top) 10th, 25th, 50th (median), 75th and 90th percentiles. Values below 10th and above 90th percentiles are plotted as circles. In years 1-5 subjects with $\mathrm{FEV}_{1}$ reversibility at enrolment showed significantly lower slope values ( $p=0.01$, Mann-Whitney $U$-test). No significant effect of reversibility was observed on $\mathrm{FEV}_{1}$ slopes for years 6-10.

A significant reduction in $\mathrm{FEV}_{1}$ variability was observed during the follow-up: median $\mathrm{FEV}_{1}$ variability at the 5 th and 10th years was significantly lower than that of the 1st year $(p<0.0001$, respectively, Wilcoxon test). In addition, a significant difference was found between the 5 th and 10 th years $(p=0.02$, Wilcoxon test). (Figure 6$)$.

Analysing exacerbation score, the prevalence of frequent exacerbators was $12 \%, 15 \%$ and $10 \%$, at 1 st, 5 th and 10 th year, respectively, with a significant difference in frequency distribution between 1st and 10th years $\left(p=0.004, \chi^{2}\right)$, and between 5th and 10th years $\left(p=0.001, \chi^{2}\right)$. No significant difference between 1 st and 5 th years was found. Frequent exacerbators in the 1st year had steeper $\mathrm{FEV}_{1} / \mathrm{Ht}^{3}$ slopes in the 1st period $(p=0.01$, Mann-Whitney $U$ test) but no effect was found on 2nd period slopes. Analysing ICS scores across the follow-up, we found that the number of subjects using higher doses of ICS was significantly lower at the 10th years respect to the 5th and to the 1st year $\left(p<0.0001, p=0.003 ; \chi^{2}\right.$, respectively) and at the 5 th year respect to 1 st year $\left(p<0.02 ; \chi^{2}\right)$, with a complementary increase of subjects using lower doses in the corresponding years. 
(Figure 7). BMI had no significant effect of age at enrolment. Disease duration, or age of disease onset was observed on $\mathrm{FEV}_{1}$ slopes in two periods. Similarly, gender, allergic sensitization and rhinitis showed no effect on $\mathrm{FEV}_{1}$ decline.

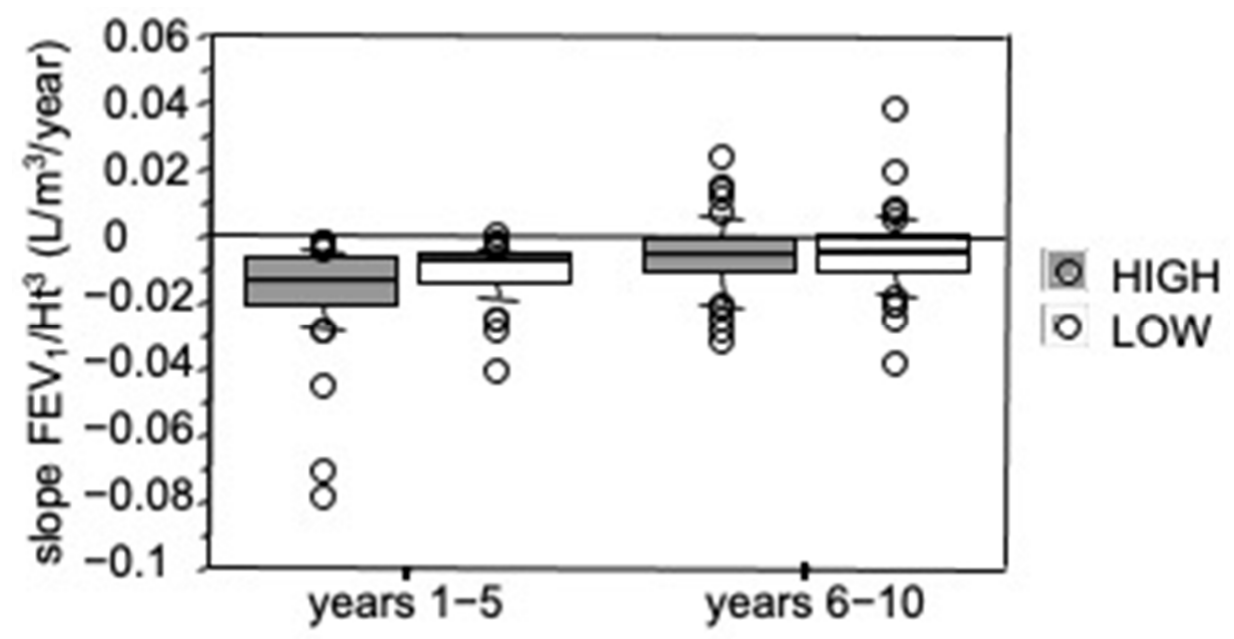

Figure 5. Slope values of relationships between height-adjusted $\mathrm{FEV}_{1}$ and time $\left(\mathrm{L} / \mathrm{m}^{3}\right.$ /year) during years $1-5$ and years $6-10$, separately for groups of $\mathrm{FEV}_{1}$ variability at 1 st year. Bars indicate (from the bottom to the top) 10th, 25th, 50th (median), 75th and 90th percentiles. Values below 10th and above 90th percentiles are plotted as circles. In years $1-5$ subjects with $\mathrm{FEV}_{1}$ variability at 1 st year showed significantly lower slope values $(p<0.04$, Mann-Whitney $U$-test). No significant effect of variability was observed on $\mathrm{FEV}_{1}$ slopes for years 6-10.

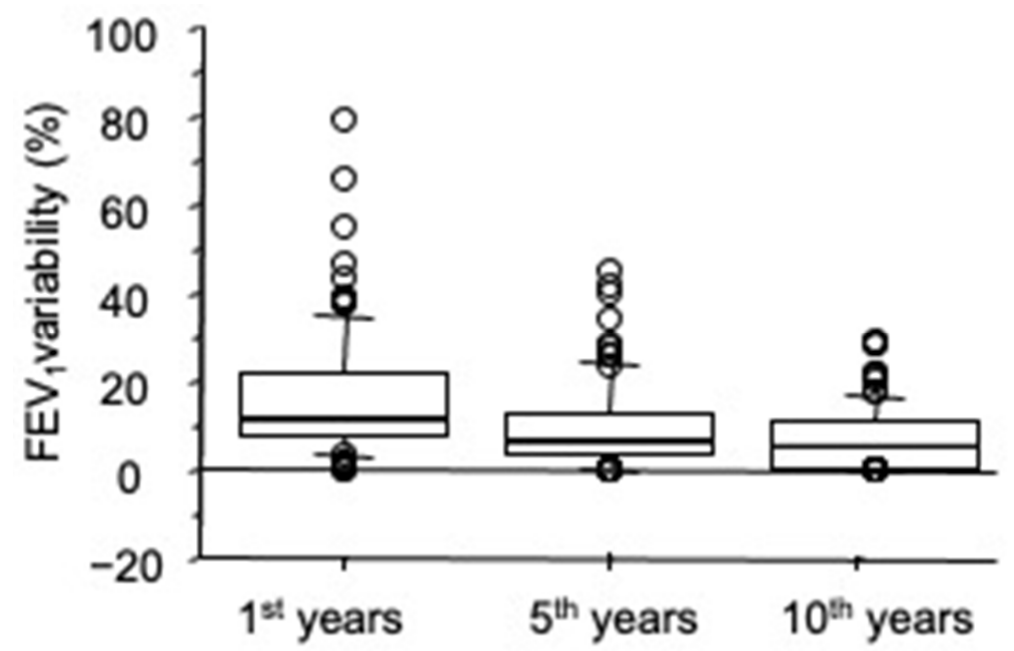

Figure 6. $\mathrm{FEV}_{1}$ variability (in percent of predicted), separately for $1 \mathrm{st}$, 5th, and 10th years. Bars indicate (from the bottom to the top) 10th, 25th, 50th (median), 75th, and 90th percentiles. Values below 10th and above 90th percentiles are plotted as circles. Significant differences were found between 1 st and 5 th years, between 1 st and 10 th years and between 5 th and 10th years (Wilcoxon test). 


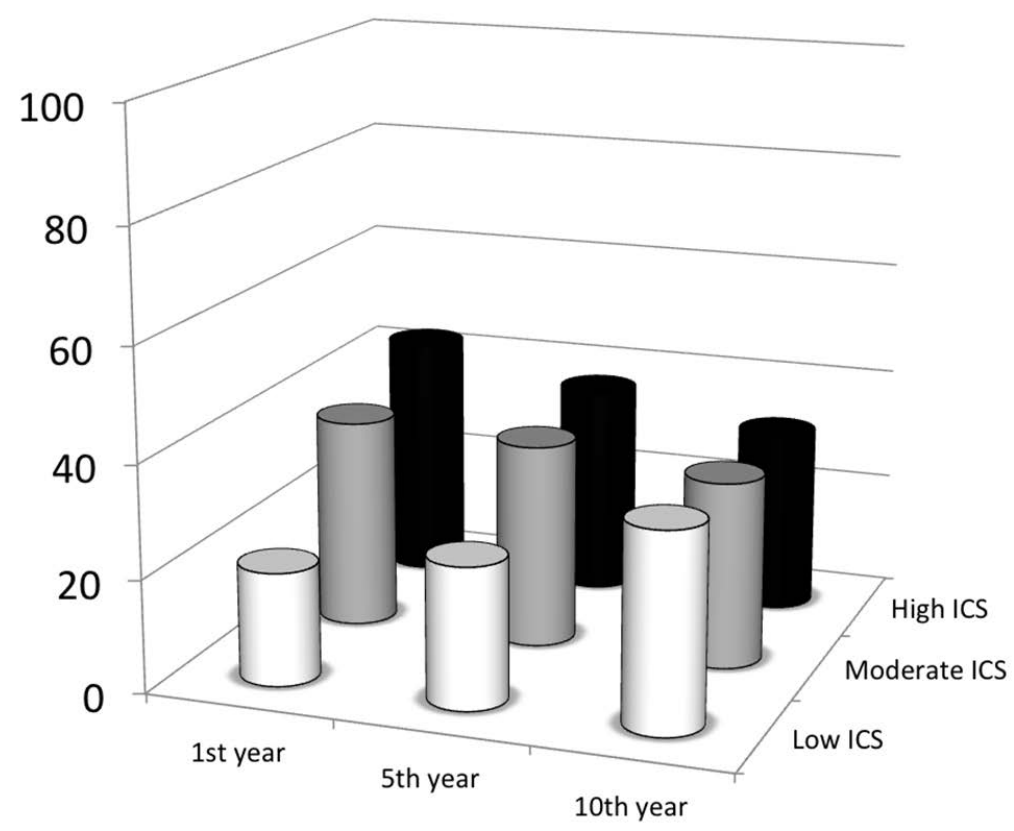

Figure 7. Prevalence of subjects, for each inhaled corticosteroid (ICS) score during the follow-up period. A Scheme of 10th and 5th years $\left(p<0.0001, \chi^{2}\right)$, between 10th and 1st years $\left(p=0.003, \chi^{2}\right)$, and between 5 th and 1 st years $\left(p<0.02, \chi^{2}\right)$.

\section{Discussion}

This longitudinal study was carried out on 100 lifelong non-smoking adult asthmatic outpatients with a well-defined clinical and functional diagnosis of bronchial asthma. They had a clinical and pulmonary function evaluations every 3 months during a 10-year follow-up.

Our results indicate that $\mathrm{FEV}_{1}$ decline in treated asthmatics over the follow-up period was not constant, but rather slowed over time. Whereas a steeper decline was observed during the 1st period, the decline was much slower in the 2nd period. Moreover, while $\mathrm{FEV}_{1}$ decline in the 1st period was influenced by reversibility, $\mathrm{FEV}_{1}$ at enrolment, $\mathrm{FEV}_{1}$ variability in the 1st year, and exacerbations in the 1st year, in the second period it was not. Furthermore, we found an overall decrease over the time in the number of subjects using high/moderate daily doses of inhaled steroids.

When decline was separately computed in the two periods, it showed a striking intraindividual difference: mean $\mathrm{FEV}_{1}$ loss was $42.5 \mathrm{~mL} /$ year in the 1 st period and $25.5 \mathrm{~mL} /$ year per year in the 2nd. Thus, mean $\mathrm{FEV}_{1}$ decline in the 2nd period was $54 \%$ lower with respect to the 1st period. Our study produces different results with respect to previous papers. Peat et al. in an 18-year population health survey reported a loss of $50 \mathrm{~mL} /$ year in males (average height $1.70 \mathrm{~m}$ ) with asthma and a loss of $35 \mathrm{~mL} /$ year in normal subjects [15]. Moreover, Lange et al., in a 15-year follow-up study [17] found a loss of $38 \mathrm{~mL} /$ year in adult asthmatics and $22 \mathrm{~mL} /$ year in non-asthmatics. In a 10-year longitudinal study, Burrows et al. (1) found a $70 \mathrm{~mL} /$ year mean overall rate of decline in COPD subjects and $65 \mathrm{~mL} /$ year in asthmatics. Contoli [18] more recently, in a 5-year follow-up, reported a rate of $\mathrm{FEV}_{1}$ decline of $50 \mathrm{~mL} /$ year in asthmatics with fixed airflow obstruction and of 18 $\mathrm{mL} /$ year in asthmatics with reversible airflow obstruction.

We supposed that important factors could have influenced the differences in the extent of $\mathrm{FEV}_{1}$ loss, such as: (I) incorrect diagnosis (mainly asthma vs. COPD) due to limitations of selected methods (e.g., self-reported diagnosis, questionnaire); (II) inclusion of functional values collected during exacerbations; (III) few functional measurements over the follow-up; (IV) analysis performed on the entire follow-up period; (V) variable effect of pharmacological control of bronchoconstriction over time; and (VI) inclusion of current and former smokers. 
We tried to overcome these factors by means of (I) a well-defined asthma diagnosis; (II) four spirometries per year, to minimize the "learning" effect and decrease the risk of decline overestimation due to changes in disease control over time; (III) excluding both current and former smokers; (IV) separate analysis of the 1st and 2nd period of the follow-up to highlight the effect of pharmacological control over time.

All patients were lifelong non-smokers in order to avoid the interaction and detrimental effects of smoking $[19,20]$ on the $\mathrm{FEV}_{1}$ decline [21]. Moreover, a typical trajectory of age-related $\mathrm{FEV}_{1}$ decline were related to a change in the lifestyle related risk factors, BMI and smoking, these have significantly impact aging-related decline of lung function [22].

In agreement with a previous study [23], we found an inverse relationship between $\mathrm{FEV}_{1}$ decline in the 1 st period and FEV1 at enrolment, the same result was obtained for $\mathrm{FEV}_{1}$ decline in the 2nd period: a steeper $\mathrm{FEV}_{1}$ decline in subjects with higher baseline $\mathrm{FEV}_{1}$ values. We surmised that the decline can no longer be progressive after the $\mathrm{FEV}_{1}$ had previously dropped to a considerable extent.

Acute salbutamol reversibility was not associated with $\mathrm{FEV}_{1}$ decline. This lack of association could be explained by the presence of airway inflammation. In fact, when considering long term reversibility (evaluated after trial with OS), we found that subjects with reversibility showed a steeper $\mathrm{FEV}_{1}$ decline in the 1 st period, but not in the 2 nd. Ulrik et al. reported similar results observing that a high degree of reversibility was associated with a steeper functional decline in asthmatics over the following 10 years [21]. Vollmer et al. reported that the response to an inhaled bronchodilator correlated with the rate of $\mathrm{FEV}_{1}$ decline only in subjects classified as having bronchial hyperresponsiveness [24]. In our study, using $\mathrm{FEV}_{1}$ variability at 1 st year, as an expression of bronchial hyperresponsiveness, we found that it was the strongest predictor of lung function decline in the 1st period but not in the 2nd, agreeing with previous studies showing that higher airway responsiveness was responsible for accelerated $\mathrm{FEV}_{1}$ decline [25-27].

We hypothesized that greater variability of lung function over time is a marker of poorly controlled asthma, thus significantly affecting the rate of $\mathrm{FEV}_{1}$ decline. We found that the reduction of $\mathrm{FEV}_{1}$ decline over time was associated with a progressive reduction in $\mathrm{FEV}_{1}$ variability over time. In agreement with Metha et al., we suggest that the reduction in bronchial hyperresponsiveness produced and maintained by a regular ICS treatment may be responsible for the changes [28]

Moreover, a well-defined effect of ICS on the rate of decline in lung function has been reported, while the effect of bronchodilators was less conclusive, so we choose to analyse only the effect of ICS $[29,30]$.

Observational studies, showed a less pronounced decline in $\mathrm{FEV}_{1}$ in asthmatics taking ICS compared to those not receiving them [17]. Moreover, an early and regular ICS, introduced when symptoms are mild, was expected to prevent lung function worsening suggesting that ICS could reduce the intensity of airway remodelling and thus produce slower lung function decline $[8,31]$

Our results demonstrate that the step-down approach to long-term asthma therapy, grants asthma control along with a positive effect on lung function decline. In fact, despite the large increase in the number of subjects assuming a low ICS dose in the 2nd period with respect to 1 st one (19 to $38 \%$ ), the overall $\mathrm{FEV}_{1}$ decline resulted less negative [32].

Previous studies have reported a strong effect of ICS to prevent asthma exacerbations [33,34], accordingly, we found a reduction of number of high exacerbators over the follow-up period. We surmised that the significant reduction of $\mathrm{FEV}_{1}$ loss in years 6-10 with respect to years 1-5 could be due to early and regular ICS treatment of our patients [29]. We did not find any effect of disease duration on rate of decline in both periods. It is possible that asthmatics may have an excessive functional decline prior to the time of diagnosis, and also in the first years following asthma onset [3]. Accordingly, the studied subjects had a wide range of disease duration, and we could not clearly document which treatment had been adopted. 
In the last decades a growing interest was reported in the lung microbiota. Previous studies reported a shift in the lung microbiota during lung diseases, in particular in asthma [35]. Moreover, the lung microbiota is more diverse and abundant in some subjects with asthma [35-39]. It remains a matter of debate whether we should be talking about dysbiosis, stable colonization, or infections of the lungs. Furthermore, the function and causal role of this shift in the lung microbiota in the outcome of asthma remain unclear [40]. Unfortunately, we did not study this aspect in our patients.

Ulrik and Lange showed that the rate of $\mathrm{FEV}_{1}$ decline was higher in subjects with recent asthma onset compared to subjects with chronic asthma, as well as in men compared to women [5,6]. Controversies exist relevant to this effect on $\mathrm{FEV}_{1}$ decline [41,42] We did not find any influence of gender on $\mathrm{FEV}_{1}$ decline in either the 1st or 2nd 5-year period. The gender difference in $\mathrm{FEV}_{1}$ loss reported in previous studies could be explained by women's increased susceptibility to the lung-damaging effects of cigarette smoking and to development of chronic airway obstruction among asthmatics [19,43,44]. Therefore, we have chosen to include only lifelong non-smokers patients. Furthermore, our patients showed a comparable reversibility airflow obstruction that could explain the similar rate of $\mathrm{FEV}_{1}$ decline over time.

With regard to the influence of age on lung function decline in asthma, we did not find any influence of age on $\mathrm{FEV}_{1}$ decline either in the 1 st or 2 nd period. Similar results were reported by Peat et al. in a long follow-up study on asthmatics [15]. Conversely, in other studies, aging was found to be associated with a steeper decline in $\mathrm{FEV}_{1}[8,20]$.

In our study, BMI did not influence $\mathrm{FEV}_{1}$ decline. Conversely, Marcon A et al. [23] had reported a faster $\mathrm{FEV}_{1}$ decline in the non-obese compared with the obese: this finding could be due to a lower baseline $\mathrm{FEV}_{1}$ and the process of decline may no longer be progressive after $\mathrm{FEV}_{1}$ had previously dropped a considerable extent. This different result could be due to presence of more obese subjects in their sample (BMI > 30).

In agreement with previous studies $[15,41]$ we found that allergic sensitization does not appear to be a determinant of changes in the rate of functional decline in asthma, suggesting that inflammatory processes in the airways of patients with asthma may run their course, irrespective of allergic status.

\section{Conclusions}

The present study shows that the rate of $\mathrm{FEV}_{1}$ decline over ten years follow-up in nonsmoking adults treated for asthma proves not to be constant when calculated separately in 2 consecutive 5-year periods. In fact, it reduces over time, slowing down until it reaches an $\mathrm{FEV}_{1}$ rate of decline comparable to normal subjects. In the 1st 5-year period, $\mathrm{FEV}_{1}$ reversibility, higher $\mathrm{FEV}_{1}$ variability and exacerbations are determinant factors, while in the 2 nd period those factors are no longer determinant.

These findings suggest the possible role of early, continuous, and regular long-term treatment with ICS in reducing number of high exacerbators over the follow-up period, the intensity of airway remodelling and thus produce slower lung function decline in asthma patients [45].

Author Contributions: Conceptualization, G.C., S.B. and F.C.; data curation, G.C.; Formal analysis, G.C., P.A. (Pietro Alfano), P.A. (Palma Audino). and. S.M.; methodology, G.C. and F.C.; project administration, G.C. and G.F.; supervision, G.C., S.B., P.A. (Pietro Alfano) and G.F.; validation, G.C., S.B., S.M. and G.F.; visualization, G.C., S.B. and P.A. (Palma Audino); writing-original draft, G.C., S.B. and F.C.; writing-review and editing, G.C., S.B., P.A. (Pietro Alfano) and G.F. All authors have read and agreed to the published version of the manuscript.

Funding: This research was funded by Institute of Research and Biomedical Innovation (IRIB), Italian National Council (CNR), Palermo, Italy.

Institutional Review Board Statement: The study was conducted according to the guidelines of the Declaration of Helsinki and approved by the Institutional Ethics Committee (authorization reference number 7/2013). 
Informed Consent Statement: Informed consent was obtained from all subjects involved in the study.

Data Availability Statement: Primary data are available upon request.

Acknowledgments: The authors acknowledge the patients and their families.

Conflicts of Interest: The authors declare no conflict of interest. The funders had no role in the design of the study; in the collection, analyses, or interpretation of data; in the writing of the manuscript; or in the decision to publish the results.

\section{References}

1. Burrows, B.; Bloom, J.W.; Traver, G.A.; Cline, M.G. The course and prognosis of different forms of chronic airways obstruction in a sample from the general population. N. Engl. J. Med. 1987, 317, 1309-1314. [CrossRef] [PubMed]

2. Torén, K.; Schiöler, L.; Lindberg, A.; Andersson, A.; Behndig, A.F.; Bergström, G.; Blomberg, A.; Caidahl, K.; Engval, J.E.; Eriksson, M.J.; et al. The ratio FEV1/FVC and its association to respiratory symptoms-A Swedish general population study. Clin. Physiol. Funct. Imaging 2021, 41, 181-191. [CrossRef]

3. Kanner, R.E.; Renzetti, A.D., Jr.; Klauber, M.R.; Smith, C.B.; Golden, C.A. Variables associated with changes in spirometry in patients with obstructive lung diseases. Am. J. Med. 1979, 67, 44-50. [CrossRef]

4. Ørts, L.M.; Bech, B.H.; Lauritzen, T.; Carlsen, A.H.; Sandbæk, A.; Løkke, A. Lung function in adults and future burden of obstructive lung diseases in a long-term follow-up. NPJ Prim. Care Respir. Med. 2020, 30, 10. [CrossRef]

5. Ulrik, C.S.; Lange, P. Decline of lung function in adults with bronchial asthma. Am. J. Respir. Crit. Care Med. 1994, 150, 629-634. [CrossRef]

6. Lange, P.; Parner, J.; Vestbo, J.; Schnohr, P.; Jensen, G.A. 15-year follow-up study of ventilatory function in adults with asthma. N. Engl. J. Med. 1998, 339, 1194-1200. [CrossRef]

7. Raissy, H.H.; Kelly, H.W.; Harkins, M.; Szefler, S.J. Inhaled Corticosteroids in Lung Diseases. Am. J. Respir. Crit. Care Med. 2013, 187, 798-803. [CrossRef]

8. Shimoda, T.; Obase, Y.; Kishikawa, R.; Iwanaga, T. Impact of Inhaled Corticosteroid Treatment on 15-Year Longitudinal Respiratory Function Changes in Adult Patients with Bronchial Asthma. Int. Arch. Allergy Immunol. 2013, 162, 323-329. [CrossRef]

9. Kanemitsu, Y.; Matsumoto, H.; Mishima, M. Factors contributing to an accelerated decline in pulmonary function in asthma. Allergol. Int. 2014, 63, 181-188. [CrossRef]

10. Cibella, F.; Cuttitta, G.; Bellia, V.; Bucchieri, S.; D'Anna, S.; Guerrera, D.; Bonsignore, G. Lung function decline in bronchial asthma. Chest 2002, 122, 1944-1948. [CrossRef]

11. WHO/NHLBI Workshop Report. National Institutes of Health, National Heart, Lung and Blood Institute. Global Strategy for Asthma Management and Prevention. Publication Number 95-3659. 1995. Available online: http://www.ginasthma.org (accessed on 7 February 2014).

12. American Thoracic Society. Standardization of Spirometry,1994 Update. Am. J. Respir. Crit. Care Med. 1995, 152, 1107-1136. [CrossRef] [PubMed]

13. The European Academy of Allergology and Clinical Immunology. Position paper: Allergen standardization and skin tests. Allergy 1993, 48, 48-82. [CrossRef]

14. Bellia, V.; Cibella, F.; Cuttitta, G.; Scichilone, N.; Mancuso, G.; Vignola, A.M.; Bonsignore, G. Effect of age upon airway obstruction and reversibility in adult asthmatics. Chest 1998, 114, 1336-1342. [CrossRef] [PubMed]

15. Peat, J.; Woolcock, A.; Cullen, K. Rate of decline of lung function in subjects with asthma. Eur. J. Respir. Dis. 1987, 70, 171-179.

16. Burrows, B.; Lebowitz, M.D.; Camilli, A.E.; Knudson, R.J. Longitudinal changes in forced expiratory volume in one second in adults. Methodologic considerations and findings in healthy nonsmokers. Am. Rev. Respir. Dis. 1986, 133, 974-980. [CrossRef] [PubMed]

17. Lange, P.; Scharling, H.; Ulrik, C.S.; Vestbo, J. Inhaled corticosteroids and decline of lung function in community residents with asthma. Thorax 2006, 61, 100-104. [CrossRef]

18. Contoli, M.; Baraldo, S.; Marku, B.; Casolari, P.; Marwick, J.A.; Turato, G.; Romagnoli, M.; Caramori, G.; Saetta, M.; Fabbri, L.M. Fixed airflow obstruction due to asthma or chronic obstructive pulmonary disease: 5-year follow-up. J. Allergy Clin. Immunol. 2010, 125, 830-837. [CrossRef]

19. Xu, X.; Weiss, S.T.; Rijcken, B.; Schouten, J.P. Smoking, changes in smoking habits, and rate of decline in FEV1: New insight into gender differences. Eur. Respir. J. 1994, 7, 1056-1061. [CrossRef]

20. Mohamed Hoesein, F.A.; Zanen, P.; Boezen, H.M.; Groen, H.J.M.; Van Ginneken, B.; de Jong, P.A.; Postma, D.S.; Lammers, J.W.J. Lung function decline in male heavy smokers relates to baseline airflow obstruction severity. Chest 2012, 142, 1530-1538. [CrossRef]

21. Ulrik, C.S.; Backer, V.; Dirksen, A. A 10 year follow up of 180 adults with bronchial asthma: Factors important for the decline in lung function. Thorax 1992, 47, 14-18. [CrossRef] [PubMed]

22. Van Oostrom, S.H.; Engelfriet, P.M.; Verschuren, W.M.; Schipper, M.; Wouters, I.M.; Boezen, M.; Smit, H.A.; Kerstjens, H.A.M.; Picavet, H.S.J. Aging-related trajectories of lung function in the general population-The Doetinchem Cohort Study. PLoS ONE 2018, 13, e0197250. [CrossRef] 
23. Marcon, A.; Corsico, A.; Cazzoletti, L.; Bugiani, M.; Accordini, M.S.; Almar, E.; Cerveri, I.; Gislason, D.; Gulsvik, A.; Janson, C.; et al. Therapy and Health Economics Group of the European Community Respiratory Health Survey. Body mass index, weight gain, and other determinants of lung function decline in adult asthma. J. Allergy Clin. Immunol. 2009, 123, 1069-1974. [CrossRef]

24. Vollmer, W.M.; Johnson, L.R.; Buist, A.S. Relationship of response to a bronchodilator and decline in forced expiratory volume in one second in population studies. Am. Rev. Respir. Dis. 1985, 132, 1186-1193. [CrossRef]

25. Rijcken, B.; Schouten, J.P.; Xu, X.; Rosner, B.; Weiss, S.T. Airway hyperresponsiveness to histamine associated with accelerated decline in $\mathrm{FEV}_{1}$. Am. J. Respir. Crit. Care Med. 1995, 151, 1377-1382. [CrossRef] [PubMed]

26. Juusela, M.; Pallasaho, P.; Sarna, S.; Piirilä, P.; Lundbäck, B.; Sovijärvi, A. Bronchial hyperresponsiveness in an adult population in Helsinki: Decreased FEV 1 , the main determinant. Clin. Respir. J. 2013, 7, 34-44. [CrossRef]

27. O'Connor, G.T.; Sparrow, D.; Weiss, S.T. A prospective longitudinal study of methacholine airway responsiveness as a predictor of pulmonary-function decline: The Normative Aging Study. Am. J. Respir. Crit. Care Med. 1995, 152, 87-92. [CrossRef] [PubMed]

28. Mehta, V.; Stokes, J.R.; Berro, A.; Romero, F.A.; Casale, T.B. Time-dependent effects of inhaled corticosteroids on lung function, bronchial hyperresponsiveness, and airway inflammation in asthma. Ann. Allergy Asthma Immunol. 2009, 103, 31-37. [CrossRef]

29. Carter, P.M.; Heinly, T.L.; Yates, S.W.; Lieberman, P.L. Asthma: The irreversible airways disease. J. Investig. Allergol. Clin. Immunol. 1997, 7, 566-571.

30. Prakash, Y.S.; Halayko, A.J.; Gosens, R.; Panettieri, R.A., Jr.; Camoretti-Mercado, B.; Penn, R.B. An official American Thoracic Society research statement: Current challenges facing research and therapeutic advances in airway remodeling. Am. J. Respir. Crit. Care Med. 2017, 195, e4-e19. [CrossRef]

31. Janson, C. The importance of airway remodelling in the natural course of asthma. Clin. Respir. J. 2010, 4, 28-34. [CrossRef] [PubMed]

32. O'Byrne, P.M.; Jenkins, C.; Bateman, E.D. The paradoxes of asthma management: Time for a new approach? Eur. Respir. J. 2017, 50, 1701103. [CrossRef]

33. Barnes, P.J. Efficacy of inhaled corticosteroids in asthma. Allergy Clin. Immunol. 1998, 102, 531-538. [CrossRef]

34. Lee, J.; Huvanandana, J.; Foster, J.M.; Reddel, H.K.; Abramson, M.J.; Thamrin, C.; Hew, M. Dynamics of inhaled corticosteroid use are associated with asthma attacks. Sci. Reports. 2021, 11, 14715. [CrossRef]

35. Hooks, K.B.; O'Malley, M.A. Dysbiosis and its discontents. MBio 2017, 8, e01492-17. [CrossRef] [PubMed]

36. Hilty, M.; Burke, C.; Pedro, H.; Cardenas, P.; Bush, A.; Bossley, C.; Davies, J.; Ervine, A.; Poulter, L.; Pachter, L.; et al. Disordered microbial communities in asthmatic airways. PLoS ONE 2010, 5, e8578. [CrossRef]

37. Huang, Y.J.; Nelson, C.E.; Brodie, E.L.; DeSantis, T.Z.; Baek, M.S.; Liu, J.; Woyke, T.; Allgaier, M.; Bristow, J.; Wiener-Kronish, J.P.; et al. National Heart, Lung, and Blood Institute. Airway microbiota and bronchial hyperresponsiveness in patients with suboptimally controlled asthma. J. Allergy Clin. Immunol. 2011, 127, 372-381. [CrossRef]

38. Goleva, E.; Jackson, L.P.; Harris, J.K.; Robertson, C.E.; Sutherland, E.R.; Hall, C.F.; Good, J.T., Jr.; Gelfand, E.W.; Martin, R.J.; Leung, D.Y. The effects of airway microbiome on corticosteroid responsiveness in asthma. Am. J. Respir. Crit. Care Med. 2013, 188, 1193-1201. [CrossRef]

39. Fujimura, K.E.; Lynch, S.V. Microbiota in allergy and asthma and the emerging relationship with the gut microbiome. Cell Host Microbe 2015, 17, 592-602. [CrossRef]

40. Barcik, W.; Boutin, R.C.; Sokolowska, M.; Finlay, B.B. The role of lung and gut microbiota in the pathology of asthma. Immunity 2020, 52, 241-255. [CrossRef] [PubMed]

41. Peat, J.K.; Woolcock, A.J.; Cullen, K. Decline of lung function and development of chronic airflow limitation: A longitudinal study of non-smokers and smokers in Busselton, Western Australia. Thorax 1990, 45, 32-37. [CrossRef]

42. Amelink, M.; de Nijs, S.B.; Berger, M.; Weersink, E.J.; ten Brinke, A.; Bel, E.H. Non-atopic males with adult-onset asthma are at risk of persistent airflow limitation. Clin. Exp. Allergy 2012, 42, 769-774. [CrossRef] [PubMed]

43. Backman, H.; Jansson, S.A.; Stridsman, C.; Muellerova, H.; Wurst, K.; Hedman, L.; Lindberg, A.; Rönmark, E. Chronic airway obstruction in a population-based adult asthma cohort: Prevalence, incidence and prognostic factors. Respir. Med. 2018, 138, 115-122. [CrossRef] [PubMed]

44. Chen, Y.; Horne, S.L.; Dosman, J.A. Increased susceptibility to lung dysfunction. Am. Rev. Respir Dis. 1991, 143, 1224-1230. [CrossRef]

45. Panhuysen, C.I.; Vonk, J.M.; Koëter, G.H.; Schouten, J.P.; van Altena, R.; Bleecker, E.R.; Postma, D.S. Adult patients may outgrow their asthma. A 25-year follow-up study. Am. J. Respir. Crit. Care Med. 1997, 155, 1267-1272. [CrossRef] [PubMed] 